\title{
Device for integrated diagnostics of mining machines triboelements
}

\author{
$I$ Gorlov $^{1 *}, S$ Ivanov $^{2}, V$ Knyazkina $^{2}, D$ Iakupov $^{2}$ \\ ${ }^{1}$ Tver State Technical University, 22 Nab. A. Nikitina, Tver, 170026, Russia \\ ${ }^{2}$ Saint Petersburg Mining University, 2, 21 linia, Vasilevski ostrov, Saint Petersburg, 199106, Russia
}

\begin{abstract}
This article presents the results of multiple-conditions wear-resistance tests for the antifriction bearings that are used in a milling tool. The test was performed on a one-fifth milling tool model. The tests were divided into three stages. The first testing stage included tests of a model with a new undamaged bearing. The second stage included tests of a model with a bearing that is worn out by approximately $50 \%$. The third stage included tests of a model with a completely worn out antifriction bearing. Along with vibroacoustic tests, we measured the temperatures of the tested triboelement. In this article, we provide amplitude-frequency values of vibroacoustic signals recorded during the tests of a model with an undamaged antifriction bearing, a bearing with 50\% worn-out extent, and $100 \%$ worn-out bearing. Appropriate resistance levels of complex machine elements cannot be achieved without systems of triboelements condition control. We suggest attaching temperature and vibroacoustic sensors to the critical elements of a peat winning machine that provide data for integral analysis of triboelemets condition and prevent failures when damage is recorded. Integral analysis of the technical condition of the main triboelements will allow performing the highly precise prognosis of the remaining life of a peat-winning machine, thus preventing failures in peat mining seasons.
\end{abstract}

\section{Introduction}

Peat winning machines (PWM) are mainly utilized during specific seasons. It is, therefore, unacceptable to let the machines stay idle due to the complicated technical failure in the spring-summer season. Main elements of a PWM that are highly exposed to friction must be reliable, wear-resistant, replaceable, and easily assembled.

Most of peat winning machine elements, especially working bodies and caterpillar mechanisms, operate in tough conditions and are exposed to static and dynamic load and aggressive ambience. Statistical data states that longer time in operation leads to an increase in running and breakdown maintenance, and a decrease in productiveness $[1,4]$. There is a point when repair becomes economically unfeasible and further utilization of a mining machine will only bring losses [5]. It is, therefore, advisable to modernize PWMs in order to achieve higher resistance of triboelements to reduce operational costs. Friction elements diagnostics allows determining and affecting factors that lead to the damaging and untimed breakdown of bearing surfaces. Rare and insufficiently deep diagnostics of the most important elements of a mining machine can lead to time-consuming repairs in a harvest season which cannot be sped up even with the help of modern repair methods $[6,7]$.

To promote safe and reliable operation of a peat winning machine, it is important to use systems for integral diagnostics of major important elements. Such systems will monitor the condition of controlled mechanisms and there is a decline from standard values, thus allowing responding timely on a possible breakdown [8].

\section{System of integral diagnostics}

The most important triboelements are wheelbase bearings and mining organs bearings. As of today, the condition of such elements stays unmonitored. In some fields, e. g. railway transport, automatic systems of temperature control are used. Such systems often record temperature data received from the sensors embedded in the bearing box. The control system processes received data and alerts of critical temperatures of bearings. Modern systems only monitor the temperature of an element and notify operators about temperature values. This information is not sufficient to analyse the possible damage inflicted to a bearing and, therefore, the change in bearing condition. In-depth analysis of a bearing element condition requires an integrated system of temperature control and carrying out a vibroacoustic analysis. These measures can be performed only with the use of improved hardware and computing tools [9].

Vibroacoustic analysis allows receiving data on the current condition of the bearing element and the extent of the bearing runout. Moreover, this module will allow

\footnotetext{
* Corresponding author: gorloviv@yandex.ru
} 
real-time monitoring of mining organs conditions, thus enhancing the reliability of the system [10].

Vibroacoustic control requires applying a specifically designed apparatus consisting of sensors and a computing unit. To reduce operational costs, such apparatus can be installed on newly produced mining machines or can be embedded in major elements of machines put on maintenance or reconstruction [2].

A module designed for railway transport utilizes modern computing units that allowed reducing instalment costs and using a broader range of software. Moreover, such apparatus has a relatively small size that makes it possible to be installed in currently utilized triboelements without bringing significant alterations in the construction [20].

Design and production of temperature and vibroacoustic analysis systems for integral control of the bearing condition in train carriages are carried out by OOO KSK Elcom [11, 16].

The system allowing performing vibroacoustic analysis consists of the following functional subsystems:

- $\quad$ sensors installed in bearing boxes and carriage body;

- central computing unit, set in a specific place in the carriage;

- $\quad$ cable lines for sensor-carriage connection.

Condition monitoring of bearing boxes is performed by sensors capable of recording temperature and vibroacoustic data. The sensor construction includes a thermal-sensitive element, an acceleration transducer, and a computing unit. A thermal-sensitive element is placed into a thermal conductive shell. An acceleration transducer and computing units are placed into the main body of a sensor. The sensor is attached to the bearing box and fixed in a specific position $[17,18,19]$.

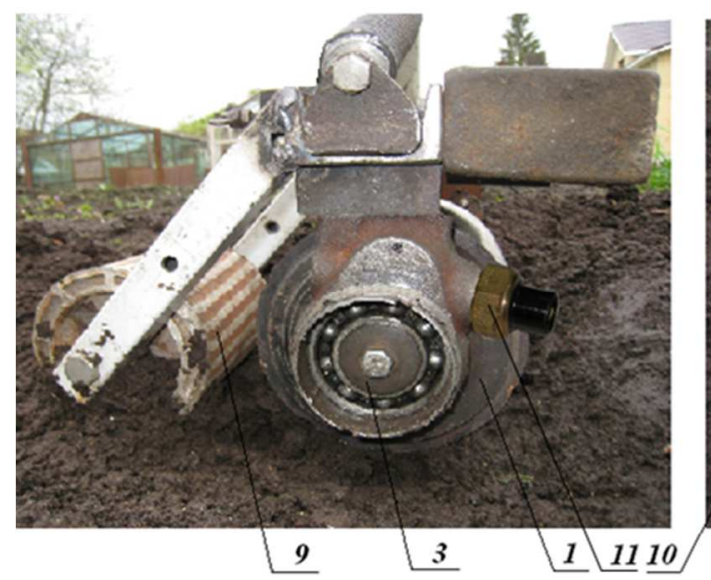

When power supplied, the thermal-sensitive element and the acceleration transducer frequently report data to the computing unit. Temperature values are recorded in centigrades and vibroacoustic signal is translated as discrete amplitude-time values or as a spectrum range. The computing unit is based on 32 bit ARM MCU. The connection between sensors and the central block is single-line, half-duplex with variable data rates $[12,3]$.

The central computing unit has a steel body with an LCD screen, light indicators, and a wireless key port at the front side. Side surfaces of the unit contain power, signal and interface sockets. Inside the shell, there are modules of the power supply system, indication and computation. The unit is powered by the onboard electric system. For enhanced reliability, the connection of the unit with the sensors is established on four independent lines. Information on bearing box elements is reflected in display and additionally sound and light indicated. The unit can be connected to the onboard computing system, thus being remotely controlled. Unit setting up and software updating can be performed through USB interface in the unit with the help of a computer or remotely through the onboard computing system. For data storing, a power independent SD-card is installed in the unit $[13,14]$.

\section{Materials and methods}

The vibroacoustic analysis allows accurately monitoring a technical condition of a tested element and estimating changes in its performance [15]. The process of changes in the technical condition of an antifriction bearing installed in a milling mechanism under various impact factors was tested on a one-fifth model (fig. 1). A milling drum 1 of a model was installed in a pin-jointed frame 2 with a bearing element 3 . A milling model was driven by a commutator motor 4 through a clutch 5 .

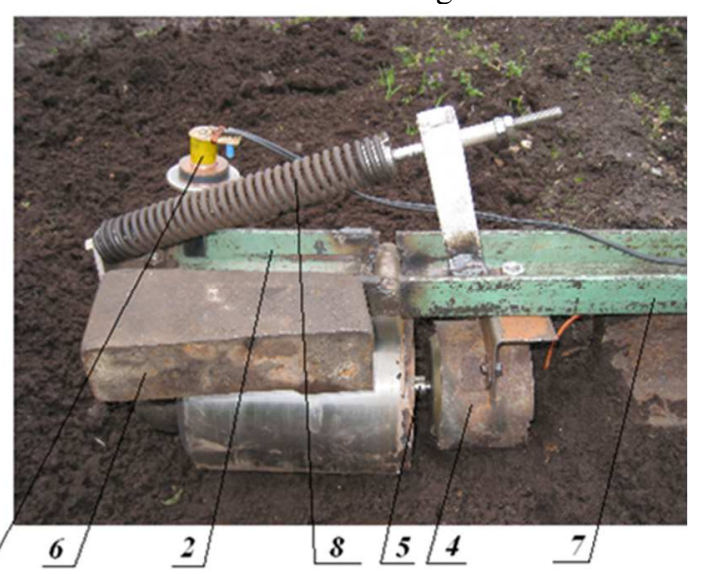

Figure 1. View illustration of a milling mechanism model

To comply with a real weight ratio of a model and a real milling mechanism, an additional load was set on a pin-jointed frame 6 . The pin-jointed frame was attached to the central frame 7 and suspended by a coil spring 8 that compensated the weight of the pin-jointed frame with a milling mechanism and a roller 9. The vibroacoustic signal was measured with a variable inductance transducer 10 and temperature values were recorded with a sensor 11 . The sensors were connected with adaptors to a laptop.

Tests were divided into three stages. The first testing stage included tests of a model with a new undamaged bearing. Fig. 2 shows the amplitude-frequency response characteristic of a vibroacoustic signal of a new bearing. 
Fig. 2 shows that the larges amplitude of the vibroacoustic signal is recorded at the drum rotation rate frequency, which tells us that the drum is imbalanced. There are also some peaks achieved at other frequencies. One can use a vibroacoustic signal frequency calculator for antifriction bearings suggested by Konstantin Zamaraev to determine the source of the signal.

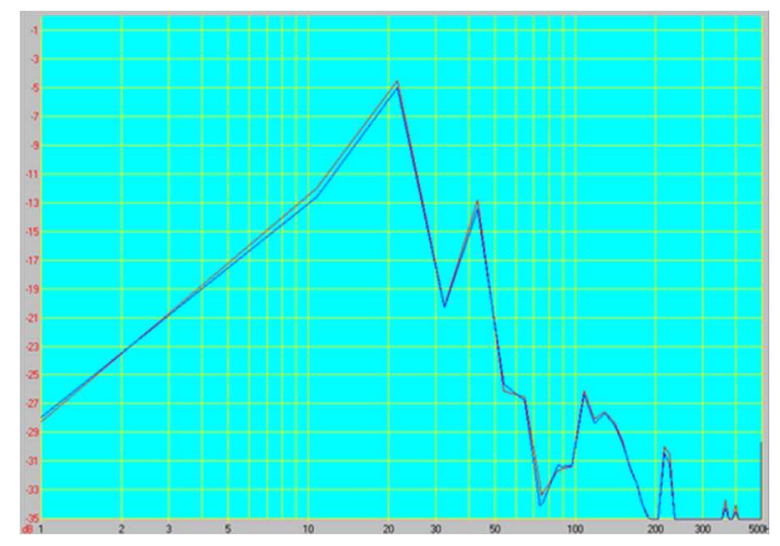

Figure 2. Amplitude-frequency response characteristic of a vibroacoustic signal recorded during the tests of a milling machine model with a new antifriction bearing

The tested antifriction bearing has a range of variations in ball diameters of $3-5 \mu \mathrm{m}$ which gives a specific vibration of $46 \mathrm{~Hz}$ frequency (the rate of ball spin). There is also a peak value at the frequency of ball spin on the inner ring.

The second stage included tests of a model with a bearing that is worn out by approximately $50 \%$. Vibroacoustic amplitudes of the corresponding frequencies grew significantly (fig. 3). Charts show that the amplitude of drum rotation rate frequency did not change, while the amplitudes of the frequencies of ball spin increased.

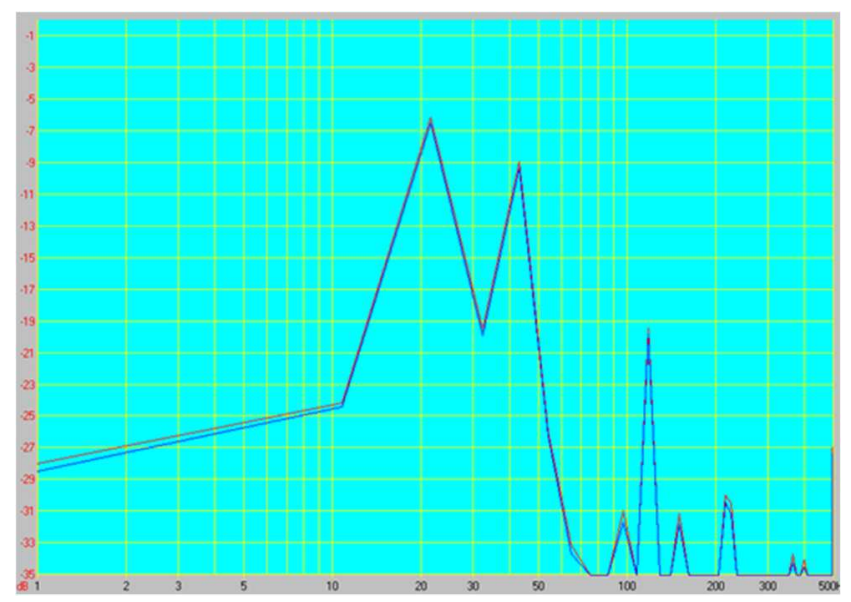

Figure 3. Amplitude-frequency response characteristic of a vibroacoustic signal recorded during the tests of a milling machine model with a partially worn out bearing

The third stage included tests of a model with a completely worn out antifriction bearing. An amplitudefrequency response characteristic of a vibroacoustic signal (fig. 4) shows the increase in almost all corresponding frequencies amplitudes. It means that the antifriction bearing is in critical condition and requires immediate replacement.

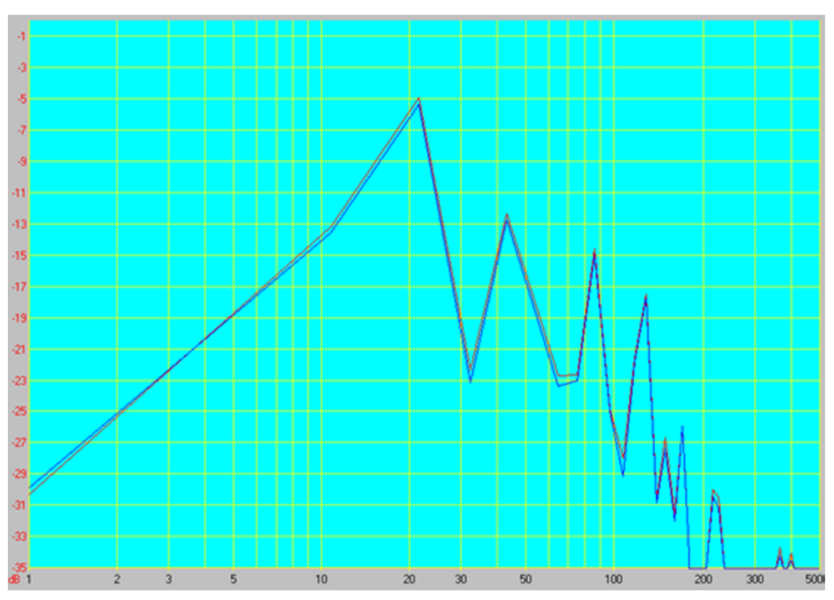

Figure 4. Amplitude-frequency response characteristic of a vibroacoustic signal recorded during the tests of a milling machine model with a totally worn out antifriction bearing

The second and the third tests showed that the extent of runout directly affected the amplitudes of all the bearing specific frequencies. It also shows the overall increase in the vibroacoustic signal values that can be used for preliminary diagnostics of an antifriction bearing.

Along with vibroacoustic tests, we measured the temperatures of the tested triboelement. Temperature values give additional information on a triboelement condition and can help to determine if it can be further used. Temperature increase can be not only a signal of an element runout, but also can indicate element overload, lack of lubricant or its poor quality, pollution, etc. Figure 5 shows the charts of temperature changes in the model antifriction bearing in course of its runout.

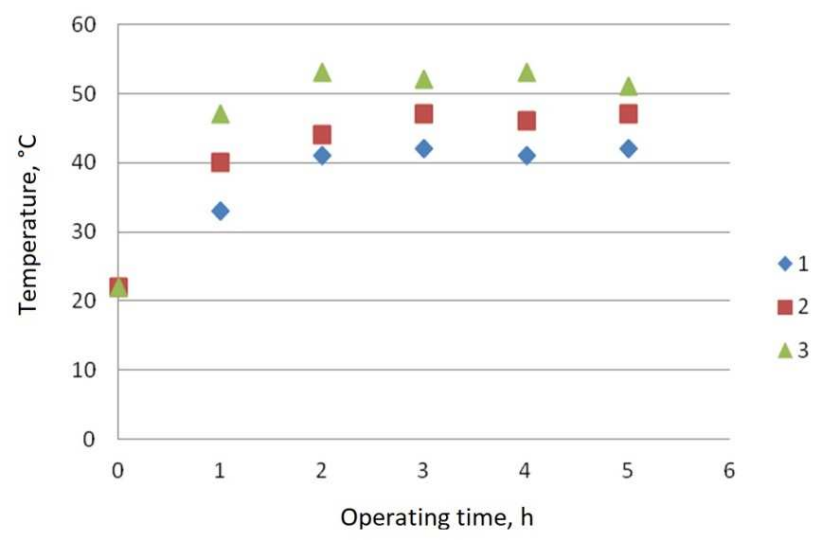

Figure 5. Change in temperatures of antifriction bearings ( 1 - new bearing, 2 - partially worn out bearing, 3 - totally worn out bearing)

After 3 hours of operation, the temperature of the tested element stabilizes. Charts also show that the highest temperature growth is recorded in the case of 
worn-out bearings. The temperatures stabilization happens at higher levels.

During tests basing on data about changes in the controlled value, it is possible to calculate a coefficient $\alpha$ that shows the ratio between the extents of change in the tested parameter and runout:

$$
\alpha_{i}=\frac{\ln \left(\Delta X_{i+1} / \Delta X_{i}\right)}{\ln \left(t_{i+1} / t_{i}\right)}
$$

where, $\Delta X_{i}$ and $\Delta X_{i+1}$ the changes in vibroacoustic signal and temperature during runout ti and ti+1.

The remaining life of the bearing can also be calculated:

$$
t_{\text {ocm }}=\frac{\Delta t\left(X_{I I P}^{1 / \alpha}-\Delta X_{i}^{1 / \alpha}\right)}{\Delta X_{i}^{1 / \alpha}-\Delta X_{i-1}^{1 / \alpha}},
$$

as well as the coefficient of changing dynamics of the tested value:

$$
K_{c i}^{1 / \alpha}=\frac{\Delta X_{i}^{1 / \alpha}-\Delta X_{i-1}^{1 / \alpha}}{\Delta t}
$$

\section{Results and Discussion}

With the high dynamics of the tested value of antifriction bearings $K_{\mathrm{ci}}$, it is hard to estimate the remaining life. It only indicates the necessity of the bearing replacement.

With periodic diagnostics of a milling machine, it is possible to determine a quite accurate timeframe in which bearings transit to significantly worn-out conditions. In such conditions, the breakdown is hardly forecasted and the detail requires replacement even if the maximum runout is not reached.

The major factor influencing the bearing condition is the imbalance of the miller that leads to a significant increase in load affecting the bearings. That is why it is recommended to diagnose the miller prior to its use and make a weighted decision about whether the mechanism can be operated or requires additional maintenance and elimination of miller imbalance. After the required repair works are carried out, additional diagnostics are recommended. In course of diagnosing, new amplitudefrequency response characteristics must be recorded. They will further serve as base values for calculating runout extents. Temperature control of triboelements allows gathering additional information on the current technical status of the bearing that is dependent on external and internal operating conditions. An increase in temperature can result not only from a significant extent of wear out but also indicate the lack of lubricant, its pollution or changes in its properties. That is why the changes in technical condition and repair requirements are determined by additional vibroacoustic signal analysis.

\section{Conclusion}

Diagnostics and further analysis of controlled parameters allow quickly estimating the current condition of the major elements of a PWM without its recovery from the peat deposit. This significantly reduces losses related to idling due to the unplanned maintenance and allows determining the remaining life of the main elements of a mining machine.

The use of integrated control and analysis systems for PWM tribolements monitoring provides all the necessary real-time data allowing performing an in-depth analysis of operating parameters changes. Thus this enhances the control over the current technical status and estimates the remaining life of the major elements preventing breakdowns during the peat harvest season.

\section{References}

1. I. Alhuraish IFAC-PapersOnLine 49 (12), 59 - 64, (2016)

2. M. Deckert Everything You Need to Know about Automatic Lubrication Systems Journal Je-bearing Retrieved from: http://www.jebearing.com/news/everything-need-knowautomatic-lubrication-systems/

3. P. B. Gerike, P. V. Esherkin High-Tech Technologies For The Development and Use of Mineral Resources 6, 150-154, (2020)

4. A. V. Mikhailov Naučno-tehničeskie Vedomosti Sankt-Peterburgskogo Gosudarstvennogo Politehničeskogo Universiteta 3(202), 229 - 235, (2014)

5. A. N. Bolotov Vestnik mašinostroeniâ 9, 67-72, (2018)

6. A. N. Gavrilin, B. B. Moizes Technological Systems Diagnostics: textbook (Tomsk Polytechnic University, Omsk, 2014)

7. A. V. Skrypnikov 2013 Modern problems of science and education (Online) 2 Retrievd from: http://science-education.ru/ru/article/view?id=8537

8. Vibration Diagnostics Retrievd from:http://vibroexpert.ru/granichnie-znacheniya-chastotnix-polostretoktavnogospektra.html

9. Bearing Failure Analysis Retrievd from: http://web.applied.com/site.cfm/Bearing_ Failure_Analysis_Operating_Conditions_Typically _Hold_Key.cfm

10. A. N. Bolotov Software \& Systems, 1, 83-89, (2016)

11. V. N. Shilovski Modern Scientific and Technical technologies, 7-1, 94-98, (2016)

12. L. N. Ivanov Mining informational and analytical bulletin 7, 51-58, (2017)

13. I. E. Berdnikov, S. P. Ozornin Modern technologies. System analysis. Modeling, 2(54), (2017)

14. V. I. Knyazkina IOP Conf. Series: Materials Science and Engineering $\mathbf{5 6 0} 012068$ (2019) doi:10.1088/1757-899X/560/1/012068.

15. S. U. Kuvshinkin, I. E. Zvonarev, P. V. Ivanova Journal of Physics: Conference Series 1118(1) 012054 (2018)

16. V. V. Nosov, E. V. Grigoriev, I. A. Pavlenko, E. R. 
Gilyazetdinov Journal of Physics: Conference Series. International Conference "Complex Equipment of Quality Control Laboratories" 012037

17. A. V. Antsupov, A. V. Jr Antsupov, V. P. Antsupov Izvestiâ Vysših Učebnyh Zavedenij. Černâ̂ Metallurgiâ 60(1), 30-35, (2017)

18. V. A. Vojtov, A. Sh. Bekirov, A. V. Voitov, B. M. Tsymbal Journal of friction and wear 40(5), 487497, (2019)

19. V. I. Savenko, O. V. Karagioz Journal of Friction and Wear 40(5), 525-534, (2019)

20. D.S. Gromyka, T.G. Utenkova, O.Y. Korotkova Mining Informational and Analytical Bulletin 2(2), 75-86, (2021) DOI:10.25018/0236-1493-2021-2-0$75-86$ 